\title{
Inhibition of miR-214 attenuates the migration and invasion of triple-negative breast cancer cells
}

\author{
YI ZHANG $^{1 *}$, ZHIJING ZHAO $^{1 *}$, SIQI LI ${ }^{1}$, LIYING DONG $^{1}$, YAN LI $^{1}$, \\ YING MAO ${ }^{1}$, YING LIANG ${ }^{1}$, YUN TAO ${ }^{2}$ and JUNFENG MA ${ }^{1}$ \\ ${ }^{1}$ Thyroid-Breast Surgery Department, The Second Affiliated Hospital of Kunming Medical University, Kunming, \\ Yunnan 650101; ${ }^{2}$ Clinical Skill Center, Kunming Medical University, Kunming, Yunnan 650500, P.R. China
}

Received May 3, 2018; Accepted November 21, 2018

DOI: $10.3892 / \mathrm{mmr} .2019 .10112$

\begin{abstract}
Triple-negative breast cancer (TNBC) is a subtype of breast cancer. MicroRNA (miR)-214 is closely associated with controlling the development of tumor cells; therefore, in the present study, the target gene and effects of miR-214 on TNBC cells were explored. Luciferase activity was examined by luciferase reporter assay. The viability, invasion and migration of MDA-MB-231 TNBC cells were measured using Cell Counting kit-8, Transwell and wound-healing assays, respectively. The expression levels of various factors were determined using reverse transcription-quantitative polymerase chain reaction and western blotting. The results demonstrated that the expression levels of miR-214 were higher and the levels of $\alpha 1$-antitrypsin ( $\alpha 1$-AT) were lower in TNBC tissues compared with in normal tissues. Subsequently, $\alpha 1-\mathrm{AT}$ was revealed to be a target of miR-214. Furthermore, inhibition of miR-214 decreased cell viability, invasion and migration, enhanced the expression of E-cadherin and tissue inhibitor of metalloproteinases-2, and reduced the expression of metastatic tumour antigen 1 and matrix metalloproteinase-2. Inhibition of miR-214 also significantly downregulated the phosphorylation of protein kinase $\mathrm{B}(\mathrm{Akt})$ and mammalian target of rapamycin (mTOR), and markedly downregulated that of phosphoinositide 3-kinase (PI3K); however, the expression levels of total PI3K, Akt and mTOR remained stable in all groups. Taken together, these findings indicated that $\alpha 1$-AT may be a target of miR-214. Downregulation of miR-214 markedly suppressed the viability, migration and invasion of MDA-MB-231 cells, and inhibited the PI3K/Akt/mTOR pathway. These findings
\end{abstract}

Correspondence to: Dr Junfeng Ma, Thyroid-Breast Surgery Department, The Second Affiliated Hospital of Kunming Medical University, 374 Dianmian Road, Wuhua, Kunming, Yunnan 650101, P.R. China

E-mail: majunf_jfm@163.com

*Contributed equally

Key words: triple negative breast cancer, miR-214, $\alpha 1$-antitrypsin, $\mathrm{PI} 3 \mathrm{~K} / \mathrm{Akt} / \mathrm{mTOR}$ pathway suggested that miR-214 targeting $\alpha 1$-AT may be a potential mechanism underlying TNBC development.

\section{Introduction}

Cancer is the second most common disease that threatens human health and mortality globally (1). Among women, breast cancer (BC) has the highest incidence of all malignant tumors (2). Triple-negative BC (TNBC) is a subtype of BC, which accounts for 10-20\% of cases of BC globally. TNBC is characterized by negative expression of estrogen receptor, progesterone receptor and human epidermal growth factor receptor 2, and is considered an independent clinicopathological type of cancer that is characterized by strong invasiveness (3-5). Metastasis is a critical biological hallmark of malignant tumors and is the leading cause of mortality among patients with TNBC (6-8); however, the specific process and underlying mechanism remains unclear. Therefore, further study of the mechanism underlying TNBC metastasis and exploration of its effective prevention are of great significance in terms of improving the survival rate and quality of life for patients.

MicroRNAs (miRNAs/miRs) are non-coding single-stranded RNA molecules, which consist of $\sim 22$ nucleotides (9). The role of miRNAs is fulfilled by regulating the expression of target genes, which is regulated by complementary binding of the miRNA to the 3'-untranslated region (3'UTR) of the target gene mRNA $(10,11)$. miRNAs may act as oncogenes or tumor suppressor genes in the development of cancer (12-15). Numerous studies have reported that the abnormal expression of miRNAs is closely associated with the development of various tumor types (13-18), and miRNAs are expected to be a novel molecular target for the diagnosis and treatment of cancer. The abnormal expression of miR-214 contributes to the formation of various human tumors, including ovarian cancer, colorectal cancer, gastric cancer and BC (19-22). Furthermore, miR-214 is closely associated with regulation of the development of tumor cells, including cell growth, apoptosis and metastasis (21,23-25); however, at present, the role and target of miR-214 in TNBC is not fully understood.

The phosphoinositide 3-kinase (PI3K)/protein kinase B $(\mathrm{Akt}) / \mathrm{mammalian}$ target of rapamycin (mTOR) signal 
transduction pathway is one of the most important signaling pathways in cells. This pathway serves a vital role in regulating cell proliferation, apoptosis, differentiation and metabolism by affecting the activation state of several downstream effector molecules (26-28). In recent years, abnormal activation of the PI3K/Akt/mTOR pathway has been detected in numerous human malignant tumors, and activation of this pathway may be a critical factor leading to the proliferation and metastasis of tumor cells (29-31).

In the present study, the target gene of miR-214 in TNBC was analyzed using the microRNA.org website. In addition, the effects of miR-214 on the growth and metastasis of TNBC cells, and the associated pathways were analyzed.

\section{Materials and methods}

Tissue collection. Between June 2016 and November 2017, 37 TNBC, 37 non-TNBC BC and 37 normal tissues were collected from patients with TNBC (38-55 years), patients with n-TNBC (35-53 years) and normal control individuals (all female, 36-52 years) who were diagnosed and subjected to mastectomy at the Second Affiliated Hospital of Kunming Medical University (Kunming, China). All patients provided written informed consent and allowed their tissues to be used for research purposes. The present study was approved by the Ethics Committee of the Second Affiliated Hospital of Kunming Medical University.

Cell culture. The MDA-MB-231 human TNBC cell line was purchased from Cobioer Biosciences Co., Ltd. (Nanjing, China). The cells were cultured in RPMI-1640 medium (Huayueyang Biotechnology Co., Ltd., Beijing, China) supplemented with $10 \%$ fetal bovine serum (FBS; Hangzhou Sijiqing Biological Engineering Materials Co., Ltd., Hangzhou, China), and a mixture of penicillin $(100 \mu \mathrm{g} / \mathrm{ml})$ and streptomycin (100 U/ml; Beijing Solarbio Science \& Technology Co., Ltd., Beijing, China) in a 95\% humidified incubator (Sanyo Electric Co., Ltd.; Panasonic Corporation, Kadoma, Japan) containing $5 \% \mathrm{CO}_{2}$ at $37^{\circ} \mathrm{C}$.

Cell transfection. miR-214 mimics, miR-214 inhibitor and miRNA negative control (NC) were purchased from Vigene Biosciences (Rockville, MD, USA). The miRNA sequences were as follows: miR-214 mimics, 3'-UGACGGACAGACACG GACGACA-5'; miRNA inhibitor, 3'-ACUGCCUGUCUGUGC CUGCUGU-5'; and miRNA NC, 5'-UCUACUCUUUCUAGG AGGUUGUGA-3'. Cell transfection with miR-214 mimics (100 pmol), inhibitor (100 pmol) or miRNA NC (100 pmol) was performed when the confluence of MDA-MB-231 cells reached $\sim 60 \%$. Transfection was conducted using Lipofectamine ${ }^{\circledR}$ 2000 (Invitrogen; Thermo Fisher Scientific, Inc., Waltham, MA, USA) at $37^{\circ} \mathrm{C}$ for $24 \mathrm{~h}$. Reverse transcription-quantitative polymerase chain reaction (RT-qPCR) analysis was performed to confirm successful transfection.

Luciferase reporter assay. Putative targets of miR-214 were predicted using miRanda version 3.3a (microRNA. org). Luciferase activity was determined using the Dual-Luciferase ${ }^{\circledR}$ Reporter Assay (Promega Corporation, Madison, WI, USA). Briefly, 293 cells (Cobioer Biosciences
Co., Ltd.) were co-transfected with miR-214 mimics or miRNA NC and $\alpha 1-A T-3$ 'UTR or $\alpha 1-A T-3 ' U T R$ mutant (mut) plasmids (400 ng) using Lipofectamine ${ }^{\circledR} 2000$ at $37^{\circ} \mathrm{C}$ for 24 h; a QuikChange Site-Directed Mutagenesis Kit (Agilent Technologies, Inc., Santa Clara, CA, USA) was used to obtain $\alpha 1-A T-3$ 'UTR mutant. The cells were lysed using $1 \mathrm{X}$ passive lysis buffer at room temperature for $15 \mathrm{~min}$ and the suspension was transferred to the black enzyme plate. LARII $(100 \mu \mathrm{l})$ and Stop\&Glo ${ }^{\circledR}$ reagent $(100 \mu \mathrm{l})$ were then added to the plates at room temperature, and luciferase activity normalized to Renilla luciferase was immediately measured using a GloMax ${ }^{\circledR}$ Discover Multimode Microplate Reader (GM3000; Promega Corporation).

$R T$-qPCR analysis. Total RNA was extracted from cells and tissues using RNA extraction kit (Takara Biotechnology Co., Ltd., Dalian, China). Subsequently, $1 \mu \mathrm{g}$ RNA was used to synthesize cDNA using the SuperScript ${ }^{\circledR}$ VILO $^{\text {TM }}$ cDNA synthesis kit (Thermo Fisher Scientific, Inc.). The RT reaction conditions were as follows: $30^{\circ} \mathrm{C}$ for $10 \mathrm{~min}, 42^{\circ} \mathrm{C}$ for $30 \mathrm{~min}$ and $95^{\circ} \mathrm{C}$ for 5 min. cDNA was then amplified using Fast $\mathrm{SYBR}^{\circledR}$ Green Master Mix (Thermo Fisher Scientific, Inc.). The qPCR reaction conditions were as follows: $95^{\circ} \mathrm{C}$ for $10 \mathrm{sec}$, followed by 40 cycles at $95^{\circ} \mathrm{C}$ for $5 \mathrm{sec}$ and $60^{\circ} \mathrm{C}$ for $30 \mathrm{sec}$, and a final step at $75^{\circ} \mathrm{C}$ for $1 \mathrm{~min}$. Primer sequences are listed in Table I. U6 and $\beta$-actin were used as internal controls. mRNA expression levels were quantified using the $2^{-\Delta \Delta \mathrm{Cq}}$ method (32).

Western blot analysis. Total proteins were lysed from cells and tissues using radioimmunoprecipitation assay buffer (Beijing Solarbio Science \& Technology Co., Ltd.), and protein concentrations were determined using bicinchoninic acid protein assay (Thermo Fisher Scientific, Inc.). Proteins ( $1 \mu \mathrm{g} / \mu \mathrm{l} ; 10 \mu \mathrm{g} /$ lane) were separated by $12 \%$ SDS-PAGE and were transferred onto polyvinylidene fluoride membranes (Hangzhou RENO Membrane Technology, Co., Ltd., Hangzhou, China, www.renomem.com). Subsequently, 5\% non-fat milk was used to block the membranes at room temperature for $1.5 \mathrm{~h}$. The membranes were then hybridized to anti- $\alpha 1-A T$ (cat. no. ab179443, 1:1,000; Abcam, Cambridge, MA, USA), anti-E-cadherin (cat. no. ab15148, 1:800; Abcam), anti-tissue inhibitor of metalloproteinases-2 (TIMP2; cat. no. ab180630, 1:1,000; Abcam), anti-metastatic tumour antigen 1 (MTA1; cat. no. ab751, 1:1,000; Abcam), anti-matrix metalloproteinase-2 (MMP2; cat. no. ab37150, 1:1,200; Abcam), anti-phosphorylated (p)-PI3K (cat. no. ab182651, 1:1,000; Abcam), anti-PI3K (cat. no. MAB2686, 1:600; R\&D Systems, Inc.), anti-p-Akt (cat. no. MAB887, 1:800; R\&D Systems, Inc.), anti-Akt (cat. no. MAB2055, 1:800; R\&D Systems, Inc.), anti-p-mTOR (cat. no. ab109268, 1:1,000; Abcam), anti-mTOR (cat. no. ab32028, 1:1,000; Abcam) and anti- $\beta$-actin (cat. no. ab8227, 1:600; Abcam) at $4^{\circ} \mathrm{C}$ for $24 \mathrm{~h}$. Subsequently, the membranes were hybridized to the corresponding secondary antibodies (Abcam): Horseradish peroxidase (HRP)-conjugated donkey anti-mouse immunoglobulin (Ig)G H\&L (cat. no. ab6820, 1:7,000), HRP-conjugated rabbit anti-mouse IgG H\&L (cat. no. ab6728, 1:7,000) and HRP-conjugated goat anti-rabbit IgG H\&L ( cat. no. ab6721, 1:7,000) at $37^{\circ} \mathrm{C}$ for $60 \mathrm{~min}$. The blots were detected by enhanced chemiluminescence 
Table I. Primer sequences.

Primer name

Sequence $\left(5^{\prime}-3^{\prime}\right)$

Product size (bp)

miR-214-forward
miR-214-reverse
$\alpha 1$-AT-forward
$\alpha 1$-AT-reverse
E-cadherin-forward
E-cadherin-reverse
TIMP2-forward
TIMP2-reverse
MTA1-forward
MTA1-reverse
MMP2-forward
MMP2-reverse
U6-forward
U6-reverse
$\beta$-actin-forward
$\beta$-actin-reverse

ATAGAATTCTTTCTCCCTTTCC
CCAGGATCCTTTCATAGGCACCA
TCAAGGACACCGAGGAAGAG
AGGTGCTGTAGTTTCCCCTC
TTTGAAGATTGCACCGGTCG
CAGCGTGACTTTGGTGGAAA
AGCACCACCCAGAAGAAGAG
TGATGCAGGCGAAGAACTTG
CTACGACCCACAGCAGAAGA
TGGTCGATCTGCTTGTCTGT
TGGCTACACACCTGATCTGG
GAGTCCGTCCTTACCGTCAA
ACACCAAGCAGTCCGAAGAG
ACAAAATTCTCACGCCGGT
GGGAAATCGTGCGTGACATT
AGGTAGTTCGTGGATGCCA

$\alpha 1$-AT, $\alpha 1$-AT, $\alpha 1$-antitrypsin; miR-214, microRNA-214; MMP2, matrix metalloproteinase-2; MTA1, metastatic tumour antigen 1; TIMP2, tissue inhibitor of metalloproteinases- 2 .

detection reagent (Shanghai Yeasen Biotechnology Co., Ltd., Shanghai, China). VisionWorks ${ }^{\circledR}$ LS Image Acquisition and Analysis software version 7.0 (UVP, LLC, Phoenix, AZ, USA) was used to quantify band intensities.

Cell Counting kit-8 (CCK-8) assay. Cell viability was assessed by CCK-8 (Dalian Meilun Biotechnology Co., Ltd., Dalian, China). Briefly, cells were seeded in a 96-well plate $\left(3 \times 10^{3}\right.$ cells/well) at $37^{\circ} \mathrm{C}$ for $24 \mathrm{~h}$. Subsequently, cells were exposed to PBS (control), miRNA NC or miR-214 inhibitor at $37^{\circ} \mathrm{C}$ for 6,12 and $24 \mathrm{~h}$. CCK- 8 reagent $(10 \mu \mathrm{l})$ was then added to the cells, which were incubated for a further $4 \mathrm{~h}$ at $37^{\circ} \mathrm{C}$. The optical density value was then assessed at $450 \mathrm{~nm}$ using a microplate reader (SMR16.1; Uscn Life Sciences, Inc., Wuhan, China).

Wound-healing assay. Cells were seeded in a 6-well plate $\left(6 \times 10^{4}\right.$ cells/well) and were cultured for $24 \mathrm{~h}$. The cells were then exposed to PBS (control), or were transfected with miRNA NC or miR-214 inhibitor. Subsequently, the cells were scratched using a 200- $\mu 1$ pipette tip (Thermo Fisher Scientific, Inc.). Following culturing at $37^{\circ} \mathrm{C}$ for $24 \mathrm{~h}$, the cells were observed under a DSX100 optical microscope (Olympus Corporation, Tokyo, Japan).

Transwell assay. Matrigel (200 $\mu \mathrm{g} / \mathrm{ml}, 100 \mu \mathrm{l}$; BD Biosciences, Franklin Lakes, NJ, USA) was added to the upper Transwell chamber at room temperature until it solidified, after which, cells were added to the upper chamber. The medium supplemented with $15 \%$ FBS was added to the lower chamber. The transfected cells were centrifuged at 5,000 x g for $20 \mathrm{~min}$ at $4^{\circ} \mathrm{C}$, and the cell suspension $\left(2 \times 10^{5}\right.$ cells $\left./ \mathrm{ml}\right)$ was cultured in the upper chamber at $37^{\circ} \mathrm{C}$ for 24 h. Crystal violet $(0.1 \%$; Shanghai Gefan Biotechnology Co., Ltd., Shanghai, China) was used to stain the cells for $20 \mathrm{~min}$. Finally, cells were observed under a DSX100 optical microscope (Olympus Corporation).

Statistical analysis. All data are presented as the mean \pm standard error of mean, as determined by Excel 2010 (Microsoft Corporation, Redmond, WA, USA). Data were analyzed using SPSS software (version 13.0; SPSS, Inc., Chicago, IL, USA). The differences among groups were determined by one-way analysis of variance, followed by Dunnett's test. Each experiment was performed in triplicate and repeated three times. $\mathrm{P}<0.05$ was considered to indicate a statistically significant difference.

\section{Results}

Expression levels of miR-214 and $\alpha 1$-AT among patients with $B C$. RT-qPCR was used to analyze the expression levels of miR-214 and $\alpha 1-\mathrm{AT}$ in normal, n-TNBC and TNBC tissues. In $\mathrm{n}$-TNBC and TNBC tissues, the expression levels of miR-214 were higher and the mRNA expression levels of $\alpha 1$-AT were lower than in normal tissue $(\mathrm{P}<0.01$; Fig. $1 \mathrm{~A}$ and $1 \mathrm{~B})$. In addition, according to miRanda, $\alpha 1-\mathrm{AT}$ was predicted to possess an miR-214-binding site (Fig. 1C). Subsequently, it was revealed that the luciferase activity of $\alpha 1$-AT-3'UTR was reduced in cells transfected with miR-214 mimics; however, miR-214 mimics did not affect the luciferase activity of $\alpha 1$-AT-3'UTR mut (Fig. 1D). Furthermore, the expression levels of $\alpha 1$-AT were decreased following upregulation of miR-214 via transfection with miR-214 mimics (Fig. 1E-G). These results suggested that $\alpha 1-A T$ may be a target of miR-214. 

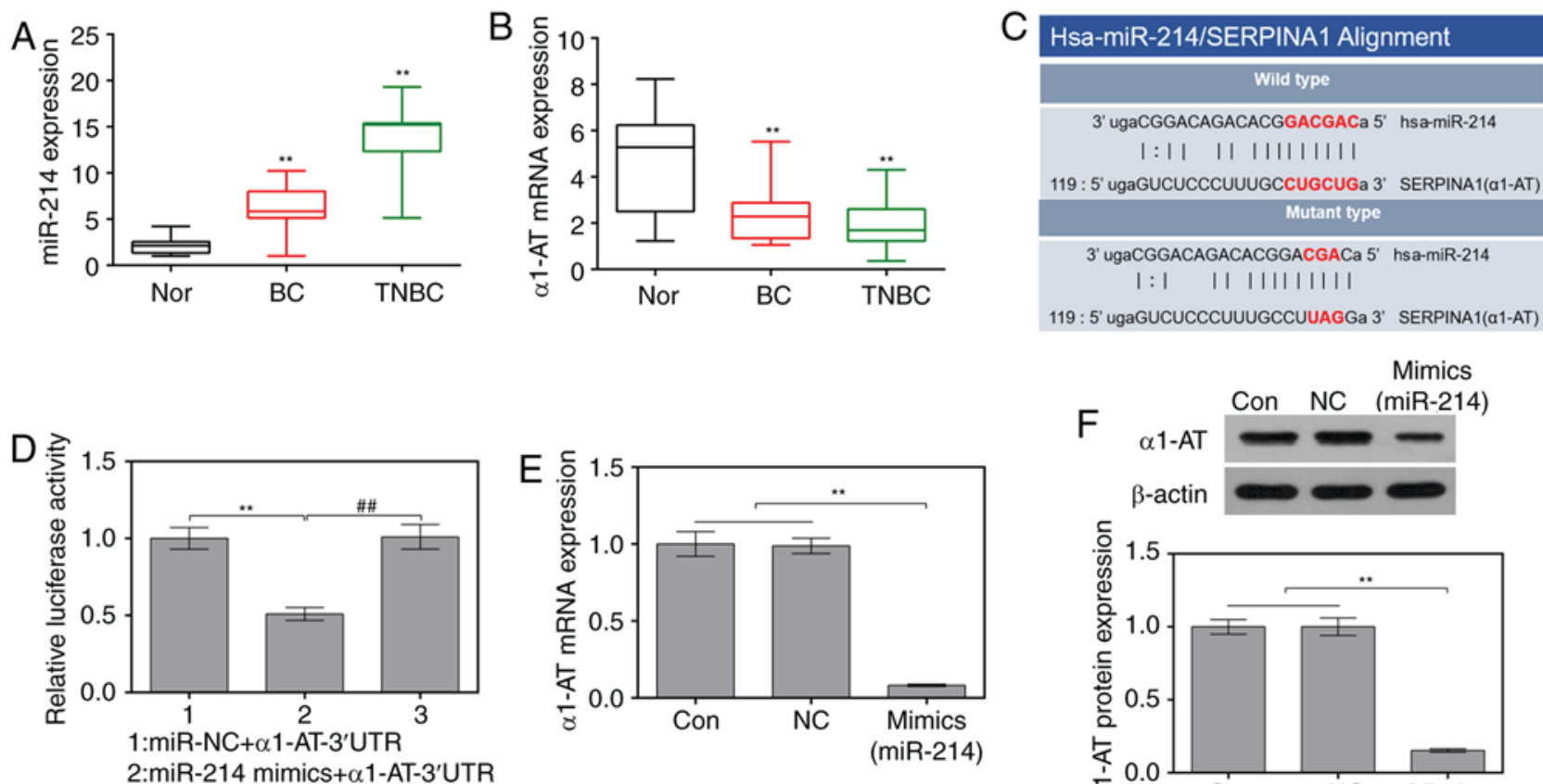

3:miR-214 mimics $+\alpha 1-$ AT-3'UTR mut

$\mathrm{G}$

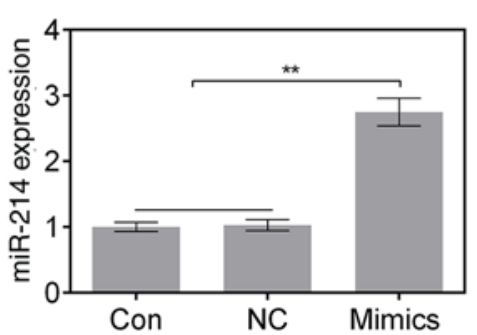

$\mathrm{H}$

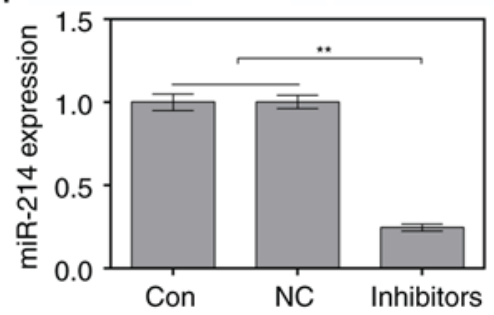

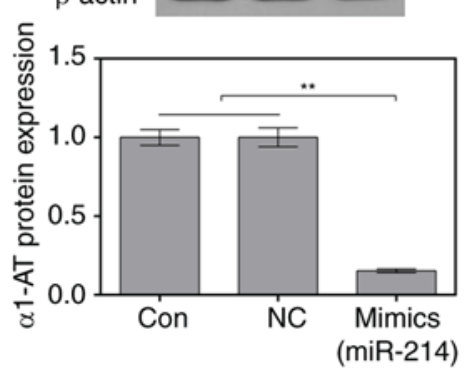

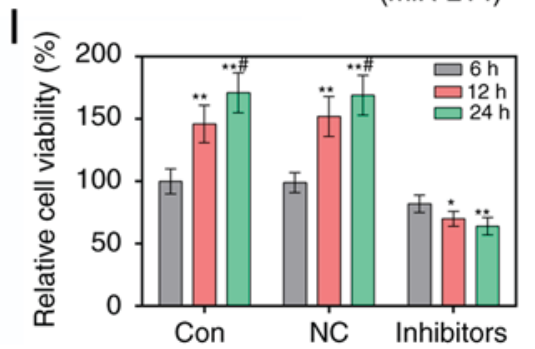

Figure 1. Suppression of miR-214 attenuates the viability of MDA-MB-231 cells. (A and B) Expression levels of Hsa-miR-214 and $\alpha 1-A T$ in normal tissues, TBNC tissues and BC tissues, as determined by RT-qPCR. ${ }^{* *} \mathrm{P}<0.01$ vs. Normal tissues $(\mathrm{C})$ Binding sites of Hsa-miR-214 and $\alpha 1-\mathrm{AT}$, as predicted by microRNA. org. (D) miR-214 mimics and $\alpha 1$-AT-3'UTR or $\alpha 1$-AT-3'UTR mut plasmids were co-transfected into 293 cells using Lipofectamine ${ }^{\circledR} 2000$. Luciferase activity was measured by luciferase reporter assay. ${ }^{* *} \mathrm{P}<0.01$ vs. miR-NC $+\alpha 1-\mathrm{AT}-3$ 'UTR group; ${ }^{\# \#} \mathrm{P}<0.01$ vs. miR-214 mimics $+\alpha 1-\mathrm{AT}-3$ 'UTR group. (E) mRNA expression levels of $\alpha 1$-AT in cells were assessed using RT-qPCR. ${ }^{* *} \mathrm{P}<0.01$ vs. control and NC cells. (F) Protein expression levels of $\alpha 1$-AT in cells were evaluated by western blotting. ${ }^{* *} \mathrm{P}<0.01$ vs. control and NC cells. (G) mRNA expression levels of miR-214 in MDA-MB-231 cells following transfection with miR-214 mimics were assessed using RT-qPCR. ${ }^{* *} \mathrm{P}<0.01$ vs. control and NC cells. (H) Expression levels of miR-214 in MDA-MB-231 cells following transfection with miR-214 inhibitors were assessed by RT-qPCR. ${ }^{* *} \mathrm{P}<0.01$ vs. control and NC cells. (I) Cell viability was determined using Cell Counting Kit-8. ${ }^{*} \mathrm{P}<0.05,{ }^{* *} \mathrm{P}<0.01$ vs. 6 h; ${ }^{*} \mathrm{P}<0.05$ vs. 12 h. 3'UTR, 3'-untranslated region; $\alpha 1$-AT, $\alpha 1$-AT, $\alpha 1$-antitrypsin; BC, breast cancer; miR-214, microRNA-214; mut, mutant; NC, negative control; RT-qPCR, reverse transcription-quantitative polymerase chain reaction; TNBC, triple-negative BC.

Suppression of miR-214 attenuates the viability of MDA-MB-231 cells. In order to examine the effects of a miR-214 inhibitor on MDA-MB-231 cells, the expression levels of miR-214 and cell viability were detected by RT-qPCR and CCK-8 assay, respectively. The results of RT-qPCR revealed that the expression levels of miR-214 were significantly decreased in cells transfected with miR-214 inhibitor (Fig. 1H). In addition, the miR-214 inhibitor markedly suppressed cell viability at 12 and $24 \mathrm{~h}$ (Fig. 1I).

Suppression of miR-214 reduces the migratory and invasive abilities of MDA-MB-231 cells. Wound-healing and Transwell assays were conducted to study the effects of a miR-214 inhibitor on the migratory and invasive abilities of MDA-MB-231 cells. As the wound-healing assay results indicated, in cells transfected with a miR-214 inhibitor, the relative wound width was markedly increased (Fig. 2A). The results of the Transwell assay indicated that the miR-214 inhibitor significantly decreased the relative invasion rate of cells (Fig. 2B).
Suppression of miR-214 regulates migration-associated factors in MDA-MB-231 cells. RT-qPCR and western blotting were performed to study the effects of miR-214 inhibition on the expression of migration-associated factors. As shown in Fig. 3A-D, the mRNA expression levels of E-cadherin and TIMP2 were increased, whereas the mRNA expression levels of MTA1 and MMP2 were decreased in cells transfected with a miR-214 inhibitor. In addition, alterations in the protein expression levels of E-cadherin, TIMP2, MTA1 and MMP2 were consistent with alterations in the mRNA expression levels (Fig. 3E).

Suppression of miR-214 inhibits the PI3K/Akt/mTOR signaling pathway in MDA-MB-231 cells. In order to investigate the effects of the miR-214 inhibitor on signaling in MDA-MB-231 cells, the PI3K/Akt/mTOR signaling pathway was examined by western blotting. The results revealed that transfection with the miR-214 inhibitor markedly downregulated phosphorylation of PI3K, Akt and mTOR. However, the expression levels of total 
A
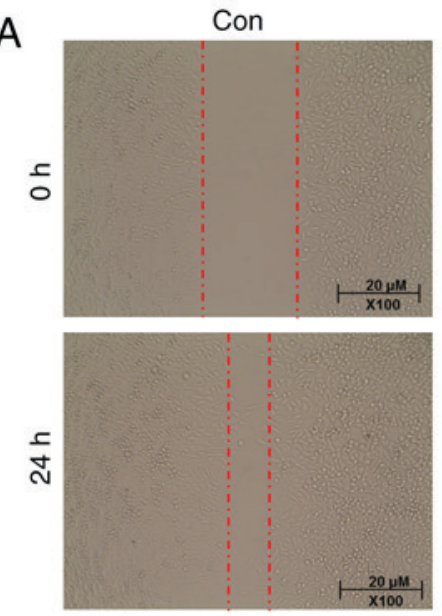

B

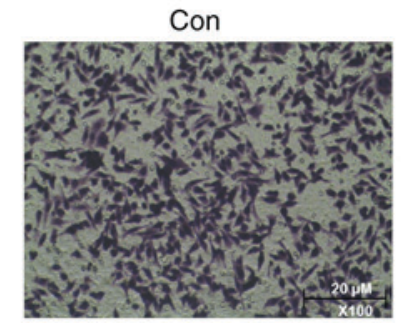

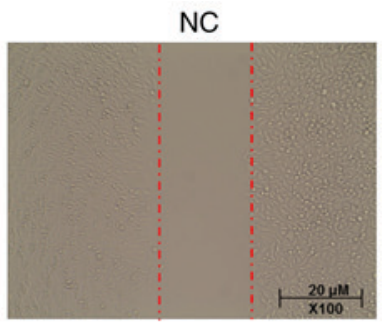
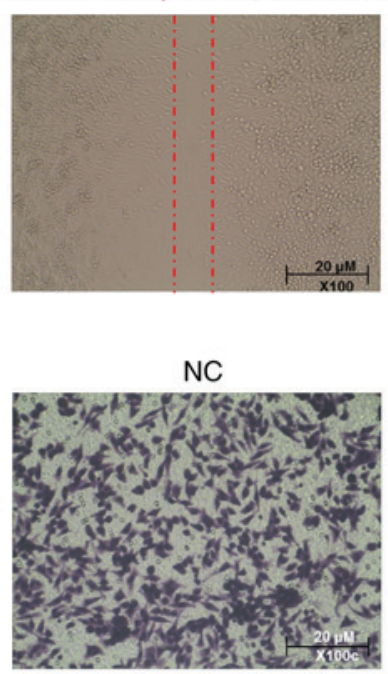
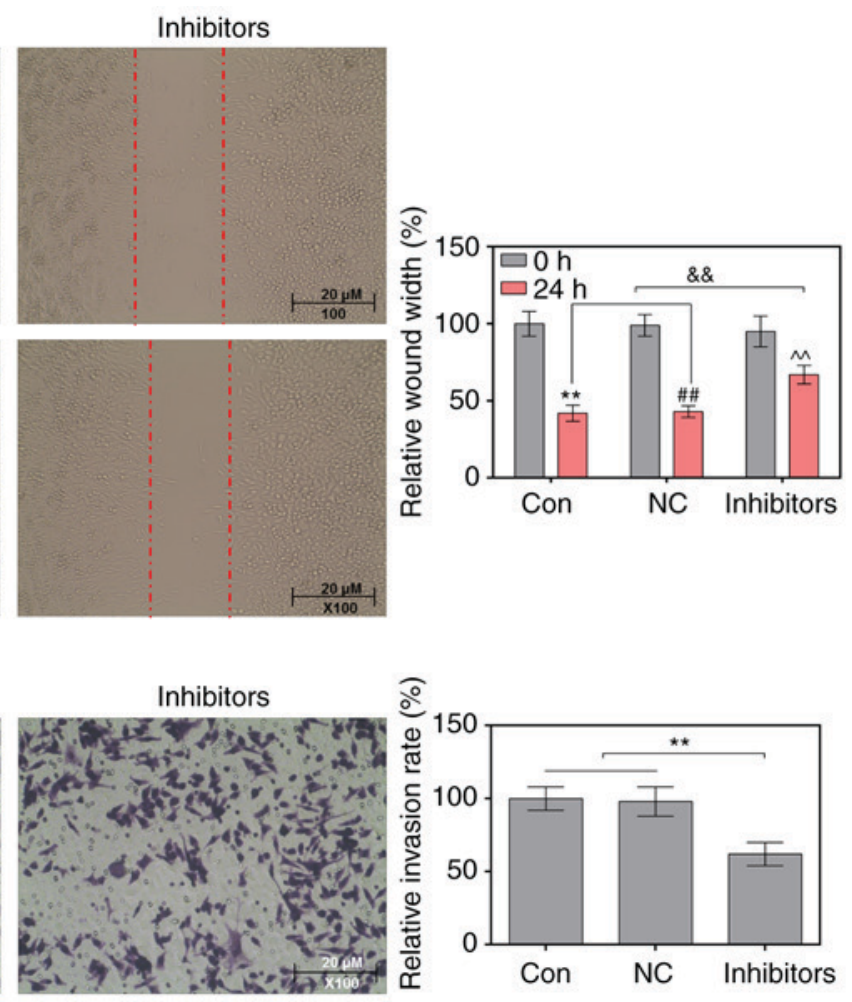

Figure 2. Suppression of microRNA-214 reduces the migratory and invasive abilities of MDA-MB-231 cells. (A) Relative wound width of cells was analyzed by a wound-healing assay. ${ }^{* *} \mathrm{P}<0.01,{ }^{\# \#} \mathrm{P}<0.01,{ }^{\wedge} \mathrm{P}<0.01 \mathrm{vs} .0 \mathrm{~h} ;{ }^{\& \&} \mathrm{P}<0.01$ vs. control and NC cells. (B) Relative invasion rate of cells, as determined by Transwell assay. ${ }^{* *} \mathrm{P}<0.01$ vs. control and NC cells. NC, negative control.

PI3K, Akt and mTOR remained stable in the various groups (Fig. 4). The proportions of p-Akt/Akt and p-mTOR/mTOR were significantly reduced by the miR-214 inhibitor (Fig. 4).

\section{Discussion}

Increasing evidence has demonstrated that miR-214 is aberrantly expressed and its function is altered in various types of tumor; in particular, low miR-214 expression has been detected in liver cancer and ovarian carcinoma $(21,33)$, whereas high miR-214 expression has been observed in BC, gastric cancer and pancreatic cancer $(20,24,34)$. Notably, Kalniete et al (20) detected high expression levels of miR-214 in patients with TNBC. Similar to this previous study, the present data demonstrated that miR-214 was highly expressed in TNBC tissues. $\alpha 1-\mathrm{AT}$ is a member of the serine protease inhibitor superfamily, which is dysregulated in lung cancer, prostate cancer and BC $(35,36)$. Previous studies have reported that $\alpha 1$-AT may act as a tumor suppressor in BC cells $(37,38)$. The present data revealed that the expression levels of $\alpha 1-\mathrm{AT}$ were decreased in TNBC tissues. According to microRNA. org, $\alpha 1-A T$ was identified as a target gene of miR-214. In addition, when MDA-MB-231 cells were transfected with miR-214 mimics, the expression levels of $\alpha 1$-AT were downregulated. Therefore, these findings suggested that $\alpha 1$-AT may be a target gene of miR-214, and that miR-214 may exert its effect on TNBC through targeting $\alpha 1-\mathrm{AT}$.

Cell proliferation, invasion and migration are known to be essential processes associated with tumor development. Wang et al (39) revealed that miR-214 increases the invasive capacity of BC cells. Zhang et al (40) also reported that miR-214 silencing decreases the proliferation of nasopharyngeal carcinoma cells. Furthermore, Xin et al (41) demonstrated that miR-214 facilitates the metastasis of gastric cancer cells. The present study explored the effects of miR-214 on the viability, invasion and migration of TNBC cells. The results demonstrated that inhibition of miR-214 significantly decreased the viability, migration and invasion of MDA-MB-231 cells.

E-cadherin is an intercellular adhesion molecule, and downregulation of E-cadherin decreases intercellular adhesion (42). The main function of MMPs is to degrade and reshape the dynamic balance of the extracellular matrix. A previous study reported that when tumor cell metastasis is inhibited, the levels of E-cadherin are upregulated and the levels of MMPs are downregulated (43). TIMPs are tissue inhibitors of the MMP family, and MTAs are also a class of critical tumor metastasis-associated genes. It has been reported that tumor necrosis factor $\alpha$ suppresses radiation-induced cell metastasis in neuroblastoma via increasing TIMP2 and E-cadherin levels, and decreasing MTA-2 and MMP levels (44). Therefore, this study examined the effects of miR-214 on the migration/invasion-associated factors using RT-qPCR and western blotting. It was revealed that miR-214 silencing decreased cell migration and invasion via upregulating E-cadherin and TIMP2, and downregulating MTA1 and MMP2.

Previous studies have demonstrated that miR-214 has a role in regulating the $\mathrm{PI} 3 \mathrm{~K} / \mathrm{Akt} / \mathrm{mTOR}$ pathway under various pathological conditions $(25,45,46)$. Liu et al $(25)$ reported that miR-214 controls the PI3K/Akt pathway via targeting phosphatase and tensin homolog in oophoroma. Zhao et al (46) 

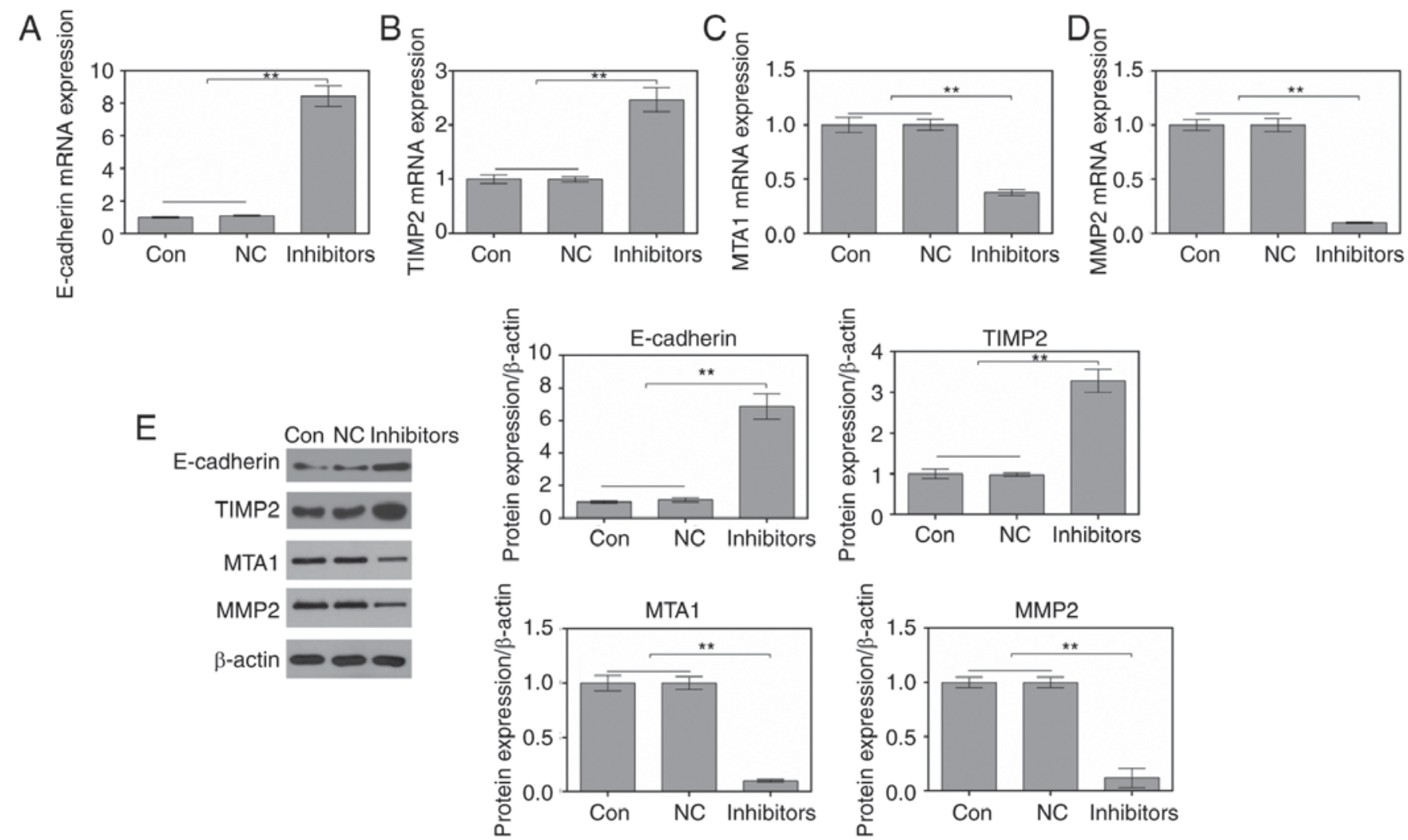

Figure 3. Suppression of microRNA-214 regulates migration/invasion-associated factors in MDA-MB-231 cells. Reverse transcription-quantitative polymerase chain reaction was conducted to detect the mRNA expression levels of (A) E-cadherin, (B) TIMP2, (C) MTA1 and (D) MMP2. (E) Western blotting was used to analyze the protein expression levels of E-cadherin, TIMP2, MTA1 and MMP2. ${ }^{* *} \mathrm{P}<0.01$ vs. control and NC cells. MMP2, matrix metalloproteinase-2; NC, negative control; MTA1, metastatic tumour antigen 1; TIMP2, tissue inhibitor of metalloproteinases-2.
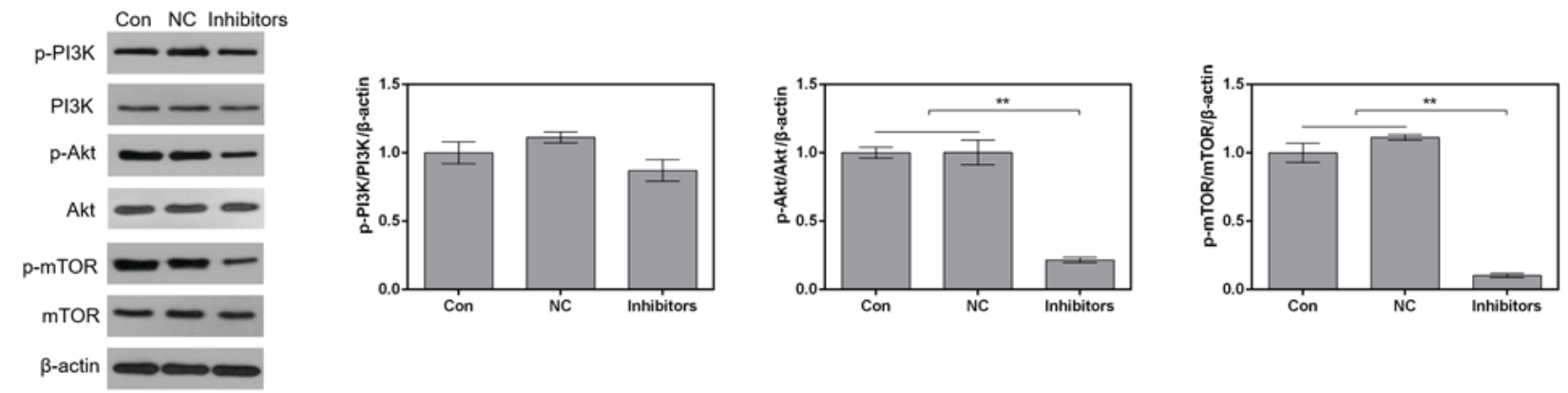

Figure 4. Suppression of miR-214 inhibits the PI3K/Akt/mTOR signaling pathway in MDA-MB-231 cells. The protein expression levels of p-PI3K, PI3K, p-Akt, Akt, p-mTOR and mTOR were determined by western blotting. The proportions of p-PI3K/PI3K/ $\beta$-actin, p-Akt/Akt/ $\beta$-actin and p-mTOR/mTOR/ $\beta$-actin were semi-quantified. ${ }^{* *} \mathrm{P}<0.01$ vs. control and NC cells. Akt, protein kinase B; mTOR, mammalian target of rapamycin; NC, negative control; PI3K, phosphoinositide 3-kinase.

also indicated that miR-214 expedited osteoclastogenesis via regulating $\mathrm{PI} 3 \mathrm{~K} / \mathrm{Akt}$ signaling. Li et al (45) demonstrated that miR-214 mediates the PI3K/Akt/mTOR signaling pathway in rat muscle atrophy. Therefore, it was hypothesized that miR-214 may mediate the PI3K/Akt/mTOR pathway in TNBC. As expected, knockdown of miR-214 suppressed the $\mathrm{PI} 3 \mathrm{~K} / \mathrm{Akt} / \mathrm{mTOR}$ pathway in MDA-MB-231 cells.

In conclusion, this study demonstrated that miR-214 was highly expressed in TNBC tissues, and that $\alpha 1$-AT was a target gene for miR-214. Silencing of miR-214 markedly suppressed the proliferation, migration/invasion of MDA-MB-231 cells by upregulating E-cadherin and TIMP2, and downregulating MTA1 and MMP2. Furthermore, miR-214 silencing inhibited the PI3K/Akt/mTOR pathway. These findings indicated that miR-214 targeting $\alpha 1$-AT may be a potential mechanism underlying TNBC development.

\section{Acknowledgements}

Not applicable. 


\section{Funding}

No funding was received.

\section{Availability of data and materials}

The datasets used and/or analyzed during the present study are available from the corresponding author on reasonable request.

\section{Authors' contributions}

JM made substantial contributions towards the design of the study. YT collected breast cancer and normal tissues. YiL performed gene expression experiments in tissues. YM performed target prediction for miR-214. YaL performed cell transfections. LD performed viability, migration and invasion assays. SL performed RT-qPCR assays. ZZ performed western blotting. YZ analyzed the data and drafted the manuscript. All authors read and approved of the final version of the manuscript.

\section{Ethics approval and consent to participate}

All patients provided written informed consent and allowed their tissues to be used for research purposes. The present study was approved by the Ethics Committee of the Second Affiliated Hospital of Kunming Medical University.

\section{Patient consent for publication}

All participants provided written informed consent prior to the present study.

\section{Competing interests}

The authors declare that they have no competing interests.

\section{References}

1. Wu J, Goyal L, Nipp R, Wo J, Qadan M and Uppot RN: The Tipping Point: Key oncologic imaging findings resulting in critical changes in the management of malignant tumors of the gastrointestinal tract. Curr Probl Diagn Radiol 48: 61-74, 2019.

2. DeSantis C, Ma J, Bryan L and Jemal A: Breast cancer statistics, 2013. CA Cancer J Clin 64: 52-62, 2014.

3. Dunne M, Dou YN, Drake DM, Spence T, Gontijo SML, Wells PG and Allen C: Hyperthermia-mediated drug delivery induces biological effects at the tumor and molecular levels that improve cisplatin efficacy in triple negative breast cancer. J Control Release 282: 35-45, 2018.

4. Park IH, Kong SY, Kwon Y, Kim MK, Sim SH, Joo J and Lee KS: Phase I/II clinical trial of everolimus combined with gemcitabine/cisplatin for metastatic triple-negative breast cancer. J Cancer 9: 1145-1151, 2018.

5. Zenzola V,Cabezas-Quintario MA,Arguelles M,Perez-FernandezE, Izarzugaza Y, Correa A and Garcia-Foncillas J: Prognostic value of Ki-67 according to age in patients with triple-negative breast cancer. Clin Transl Oncol 20: 1448-1454, 2018.

6. Farah M, Nagarajan P, Torres-Cabala CA, Curry JL, Amaria RN, Wargo J, Tawbi H, Ivan D, Prieto VG, Tetzlaff MT and Aung PP: Metastatic melanoma with balloon/histiocytoid cytomorphology after treatment with immunotherapy: A histologic mimic and diagnostic pitfall. J Cutan Pathol 45: 545-549, 2018.

7. Hejduk B, Bobek-Billewicz B, Rutkowski T, Hebda A Zawadzka A and Jurkowski MK: Application of Intravoxel Incoherent Motion (IVIM) model for differentiation between metastatic and non-metastatic head and neck lymph nodes. Pol J Radiol 82: 506-510, 2017
8. Ma J, Yang Y, Huo D, Wang Z, Zhai X, Chen J, Sun H, An W, Jie J and Yang P: LincRNA-RoR/miR-145 promote invasion and metastasis in Triple-negative breast cancer via targeting MUC1. Biochem Biophys Res Commun 500: 614-620, 2018.

9. Kumar MS, Lu J, Mercer KL, Golub TR and Jacks T: Impaired microRNA processing enhances cellular transformation and tumorigenesis. Nat Genet 39: 673-677, 2007.

10. Abdellatif M: Differential expression of microRNAs in different disease states. Circ Res 110: 638-650, 2012.

11. Pillai RS: MicroRNA function: Multiple mechanisms for a tiny RNA? RNA 11: 1753-1761, 2005.

12. Guo Y, Jiang Y, Sang M and Xu C: Down-regulation of miR-373 increases the radiosensitivity of lung cancer cells by targeting TIMP2. Int J Biochem Cell Biol 99: 203-210, 2018.

13. Li X, Zhao Z, Li M, Liu M, Bahena A, Zhang Y, Zhang Y, Nambiar C and Liu G: Sulforaphane promotes apoptosis, and inhibits proliferation and self-renewal of nasopharyngeal cancer cells by targeting STAT signal through miRNA-124-3p. Biomed Pharmacother 103: 473-481, 2018.

14. Liu X, He B, Xu T, Pan Y, Hu X, Chen X and Wang S: MiR-490-3p functions as a tumor suppressor by inhibiting oncogene VDAC1 expression in colorectal cancer. J Cancer 9: 1218-1230, 2018.

15. Polakovicova I, Jerez S, Wichmann IA, Sandoval-Borquez A, Carrasco-Veliz N and Corvalan AH: Role of microRNAs and exosomes in helicobacter pylori and epstein-barr virus associated gastric cancers. Front Microbiol 9: 636, 2018.

16. Shan X, Zhang H, Zhang L, Zhou X, Wang T, Zhang J, Shu Y, Zhu W, Wen W and Liu P: Identification of four plasma microRNAs as potential biomarkers in the diagnosis of male lung squamous cell carcinoma patients in China Med 7: 2370-2381, 2018.

17. Wang Y, Bao W, Liu Y, Wang S, Xu S, Li X, Li Y and Wu S: miR-98-5p contributes to cisplatin resistance in epithelial ovarian cancer by suppressing miR-152 biogenesis via targeting Dicer1. Cell Death Dis 9: 447, 2018.

18. Zhang T, Liu W, Meng W, Zhao H, Yang Q, Gu SJ, Xiao CC, Jia CC and Fu BS: Downregulation of miR-542-3p promotes cancer metastasis through activating TGF- $\beta /$ Smad signaling in hepatocellular carcinoma. Onco Targets Ther 11: 1929-1939, 2018.

19. Hu JL, He GY, Lan XL, Zeng ZC, Guan J, Ding Y, Qian XL, Liao WT, Ding YQ and Liang L: Inhibition of ATG12-mediated autophagy by miR-214 enhances radiosensitivity in colorectal cancer. Oncogenesis 7: 16, 2018.

20. Kalniete D, Nakazawa-Miklasevica M, Strumfa I, Abolins A, Irmejs A, Gardovskis J and Miklasevics E: High expression of miR-214 is associated with a worse disease-specific survival of the triple-negative breast cancer patients. Hered Cancer Clin Pract 13: 7, 2015.

21. Liu Y, Lin J, Zhai S, Sun C, Xu C, Zhou H and Liu H: MicroRNA-214 suppresses ovarian cancer by targeting $\beta$-Catenin. Cell Physiol Biochem 45: 1654-1662, 2018.

22. Wang X, Zhang H, Bai M, Ning T, Ge S, Deng T, Liu R, Zhang L, Ying $\mathrm{G}$ and $\mathrm{Ba}$ Y: Exosomes serve as nanoparticles to deliver anti-miR-214 to reverse chemoresistance to cisplatin in gastric cancer. Mol Ther 26: 774-783, 2018.

23. Chen X, Wang YW, Zhu WJ, Li Y, Liu L, Yin G and Gao P: A four-microRNA signature predicts lymph node metastasis and prognosis in breast cancer. Hum Pathol 76: 122-132, 2018.

24. Li HL, Liang S, Cui JH and Han GY: Targeting of GSK-3 $\beta$ by miR-214 to facilitate gastric cancer cell proliferation and decrease of cell apoptosis. Eur Rev Med Pharmacol Sci 22: 127-134, 2018.

25. Liu J, Chen W, Zhang H, Liu T and Zhao L: miR-214 targets the PTEN-mediated PI3K/Akt signaling pathway and regulates cell proliferation and apoptosis in ovarian cancer. Oncol Lett 14: 5711-5718, 2017.

26. Costa RLB, Han HS and Gradishar WJ: Targeting the PI3K/AKT/mTOR pathway in triple-negative breast cancer: A review. Breast Cancer Res Treat 169: 397-406, 2018.

27. Ramakrishnan V and Kumar S: PI3K/AKT/mTOR pathway in multiple myeloma: From basic biology to clinical promise. Leuk Lymphoma 1-11, 2018.

28. Simioni C, Martelli AM, Zauli G, Vitale M, McCubrey JA, Capitani S and Neri LM: Targeting the phosphatidylinositol 3-kinase/Akt/mechanistic target of rapamycin signaling pathway in B-lineage acute lymphoblastic leukemia: An update. J Cell Physiol 233: 6440-6454, 2018.

29. Du L, Li X, Zhen L, Chen W, Mu L, Zhang Y and Song A: Everolimus inhibits breast cancer cell growth through PI3K/AKT/mTOR signaling pathway. Mol Med Rep 17: 7163-7169, 2018. 
30. Yeh YH, Hsiao HF, Yeh YC, Chen TW and Li TK: Inflammatory interferon activates HIF-1 $\alpha$-mediated epithelial-to-mesenchymal transition via PI3K/AKT/mTOR pathway. J Exp Clin Cancer Res 37: 70, 2018

31. Zhang H, Xu HL, Wang YC, Lu ZY, Yu XF and Sui DY: 20(S)-Protopanaxadiol-induced apoptosis in MCF-7 breast cancer cell line through the inhibition of PI3K/AKT/mTOR signaling pathway. Int J Mol Sci 19: pii: E1053, 2018.

32. Livak KJ and Schmittgen TD: Analysis of relative gene expression data using real-time quantitative PCR and the 2(-Delta Delta C(T)) method. Method 25: 402-408, 2001.

33. Fan Y, Qian X and Zhang C: U/G SNP rs111904020 in 3'UTR of STAT3 regulated by miR-214 promotes hepatocellular carcinoma development in Chinese population. Tumour Biol 37: 14629-14635, 2016.

34. Kuninty PR, Bojmar L, Tjomsland V, Larsson M, Storm G, Ostman A, Sandstrom P and Prakash J: MicroRNA-199a and -214 as potential therapeutic targets in pancreatic stellate cells in pancreatic tumor. Oncotarget 7: 16396-16408, 2016.

35. El-Akawi ZJ, Al-Hindawi FK and Bashir NA: Alpha-1 antitrypsin (alpha1-AT) plasma levels in lung, prostate and breast cancer patients. Neuro Endocrinol Lett 29: 482-484, 2008.

36. Hamrita B, Chahed K, Trimeche M, Guillier CL, Hammann P, Chaieb A, Korbi S and Chouchane L: Proteomics-based identification of alpha1-antitrypsin and haptoglobin precursors as novel serum markers in infiltrating ductal breast carcinomas. Clin Chim Acta 404: 111-118, 2009.

37. García-Orad A, Arizti P, Durán L, Urcelay B and De Pancorbo MM: Alpha-1-antitrypsin phenotypes among breas cancer patients in the basque population. Hum Hered 44 203-208, 1994.

38. Lópezárias E, Aguilarlemarroy A, Felipe JL, Morganvillela G, Mariscalramírez I, Martínezvelázquez M, Alvarez $\mathrm{AH}$ Gutiérrezortega A and Hernándezgutiérrez R: Alpha 1-antitrypsin: A novel tumor-associated antigen identified in patients with early-stage breast cancer. Electrophoresis 33: 2130-2137, 2012.
39. Wang F, Lv P, Liu X, Zhu M and Qiu X: microRNA-214 enhances the invasion ability of breast cancer cells by targeting p53. Int J Mol Med 35: 1395-1402, 2015.

40. Zhang ZC, Li YY, Wang HY, Fu S, Wang XP, Zeng MS, Zeng YX and Shao JY: Knockdown of miR-214 promotes apoptosis and inhibits cell proliferation in nasopharyngeal carcinoma. PLoS One 9: e86149, 2014.

41. Xin R, Bai F, Feng Y, Jiu M, Liu X, Bai F, Nie Y and Fan D: MicroRNA-214 promotes peritoneal metastasis through regulating PTEN negatively in gastric cancer. Clin Res Hepatol Gastroenterol 40: 748-754, 2016.

42. Pieters T and van Roy F: Role of cell-cell adhesion complexes in embryonic stem cell biology. J Cell Sci 127: 2603-2613, 2014.

43. Che F, Xie X, Wang L, Su Q, Jia F, Ye Y, Zang L, Wang J, Li H, Quan Y, et al: B7-H6 expression is induced by lipopolysaccharide and facilitates cancer invasion and metastasis in human gliomas. Int Immunopharmacol 59: 318-327, 2018.

44. Aravindan S, Natarajan M, Herman TS and Aravindan N: Radiation-induced TNFalpha cross signaling-dependent nuclear import of NFKB favors metastasis in neuroblastoma. Clin Exp Metastasis 30: 807-817, 2013

45. Li G, Li QS, Li WB, Wei J, Chang WK, Chen Z, Qiao HY, Jia YW, Tian JH and Liang BS: miRNA targeted signaling pathway in the early stage of denervated fast and slow muscle atrophy. Neural Regen Res 11: 1293-1303, 2016.

46. Zhao C, Sun W, Zhang P, Ling S, Li Y, Zhao D, Peng J, Wang A, Li Q, Song J, et al: miR-214 promotes osteoclastogenesis by targeting Pten/PI3k/Akt pathway. RNA Biol 12: 343-353, 2015.

(7) $\ominus$ This work is licensed under a Creative Commons Attribution-NonCommercial-NoDerivatives 4.0 International (CC BY-NC-ND 4.0) License. 